\title{
CRESCIMENTO DE MUDAS DE ERVA-MATE FERTILIZADAS COM N, P E K
}

\section{GROWTH OF MATE TEA TREE SEEDLINGS FERTILIZED WITH N, P AND K}

\author{
Delmar SANTIN ${ }^{2}$ \\ Eliziane Luiza BENEDETTI ${ }^{3}$ \\ Gilvano Ebling BRONDANI ${ }^{4}$ \\ Carlos Bruno REISSMANN ${ }^{5}$ \\ Alessandro Góis ORRUTÉA ${ }^{6}$ \\ Luís Fernando ROVEDA ${ }^{7}$
}

\begin{abstract}
RESUMO
A redução de áreas de ervais nativos tem impulsionado a procura por mudas de erva-mate para implantação de novos ervais. Porém, existem poucos trabalhos relacionados aos níveis adequados de N, P e K para a produção de mudas de erva-mate. Com objetivo de avaliar doses de N, P e K no crescimento inicial de mudas de erva-mate, foram instalados três experimentos em casa de vegetação na UFSM-RS. Após cinco meses de estratificação as sementes foram semeadas em sementeira. Em outubro de 2004 as mudas foram repicadas para vasos com $2 \mathrm{dm}^{3}$ de solo Argissolo Vermelho-Amarelo. Os experimentos foram conduzidos em blocos ao acaso com oito tratamentos: T1-testemunha, T2-100, T3-200, T4-300, T5-400, T6-500, T7-600 e T8-700 mg do elemento testado (N, P e K) kg-1 de solo. Após 270 dias da repicagem, foram analisadas as variáveis altura total $(\mathrm{H})$, diâmetro do colo $(\mathrm{DC})$, matéria fresca da parte aérea (MFPA), matéria seca da raiz (MSR), matéria seca da parte aérea (MSPA) e matéria seca total (MST). As mudas de erva-mate responderam ao $P$ aplicado e, apresentaram o melhor crescimento, na dose média de máxima eficiência técnica de $447,5 \mathrm{mg} \mathrm{kg}^{-1}$ de $\mathrm{P}$ para as variáveis analisadas. Doses de $\mathrm{N}$ e K superiores a $100 \mathrm{mg} \mathrm{kg}^{-1}$ de substrato, mostraram-se inviáveis para produção de mudas de erva-mate.
\end{abstract}

Palavras-chave: Ilex paraguariensis; nutrição; produção de mudas.

\begin{abstract}
The significant reduction of mate native population's areas has been impelling the search for seedlings of mate tea for new mate stands implantation. However, there are few studies related to adequate levels of N, P and K for the production of seedlings of mate tea. With the objective to evaluate the nitrogen, phosphorus and potassium doses on the initial growth of seedlings of mate tea tree an experiment was installed in a greenhouse at UFSM-RS. After five months under dormancy break the seeds were sown in a seed bed. In October 2004, the seedlings were transplanted to vases filled with $2 \mathrm{dm}^{3}$ of soil, classified as an Argilic red-yellow soil. The experiment was carried out in blocks at random with eight treatments: T1-control, T2-100, T3-200, T4-300, T5-400, T6-500, T7-600 and T8-700 mg kg-1 of soil of the tested elements (N, P and K). After 270 days from transplantation, total height $(\mathrm{H})$, diameter of the collar (DC), fresh matter of the above ground part (MFPA), dry matter of the root (MSR), dry matter of the above ground part (MSPA) and total dry matter (MST), were analyzed. The seedlings produced the best growth on the average dose of $447.5 \mathrm{mg} \mathrm{kg}^{-1}$ of $P$, for all analyzed variables. However, the same was not observed for treatments with $\mathrm{N}$ and $\mathrm{K}$. Doses of $\mathrm{N}$ and $\mathrm{K}$ higher than $100 \mathrm{mg} \mathrm{kg}^{-1}$ substrate showed to be inadequate for mate tea tree seedlings productions.
\end{abstract}

Key-words: Ilex paraguariensis; nutrition; production of seedlings.

${ }^{1}$ Trabalho desenvolvido na Universidade Federal de Santa Maria, Rio Grande do Sul.

${ }^{2}$ Engenheiro Florestal, Mestrando do Programa de Pós-Graduação em Ciência do Solo, Universidade Federal do Paraná, UFPR, CEP 80035-050, Curitiba (PR), Bolsista CAPES. E-mail: desantinflorestal@yahoo.com.br

${ }^{3}$ Engenheira Agrônoma, Mestranda do Programa de Pós-Graduação em Ciência do Solo, Universidade Federal do Paraná, UFPR, CEP 80035050, Curitiba (PR), Bolsista CAPES. E-mail: elibettiagro@yahoo.com.br

${ }^{4}$ Engenheiro Florestal, Mestrando do Programa de Pós-Graduação em Engenharia Florestal, UFPR, CEP 80210-170, Curitiba (PR), Bolsista CNPq. E-mail: gebrondani@yahoo.com.br

${ }^{5}$ Engenheiro Florestal, Dr. Professor do Departamento de Solos, SCA, UFPR, CEP 80035-050, Curitiba (PR). E-mail: reissman@ufpr.br

${ }^{6}$ Engenheiro Agrônomo, Mestrando do Programa de Pós-Graduação em Ciência do Solo, Universidade Federal do Paraná, UFPR, CEP 80035050, Curitiba (PR), Bolsista Cnpq. E-mail: alessandro_gois@yahoo.com.br

${ }^{7}$ Engenheiro Agrônomo, Mestrando do Programa de Pós-Graduação em Ciência do Solo, Universidade Federal do Paraná, UFPR, CEP 80035050, Curitiba (PR). E-mail: Ifroveda@uol.com.br 


\section{INTRODUÇÃO}

A erva-mate (Ilex paraguariensis St. Hil.) é uma espécie arbórea típica das regiões subtropicais e temperadas da América do Sul e apresenta importância sócio-econômica no Brasil, especialmente para os estados de Santa Catarina, Rio Grande do Sul e Paraná. É utilizada na produção de bebidas, mas apresenta potencial para outras aplicações na indústria como corante, conservante alimentar, medicamentos, produtos de higiene e cosméticos (MACCARI e MAZUCHOWSKI, 2000). A erva-mate ocorre naturalmente em solos de baixa fertilidade, com baixos teores de cátions trocáveis, altos teores de alumínio e pH ácido (CARVALHO, 2003).

A perda de áreas de ervais por culturas agrícolas, principalmente pela soja foi significativa nas últimas décadas (DA CROCE e FLOSS, 1999). Porém, com o aumento dos custos de produção das culturas anuais, esse cenário vem mudando e o plantio de ervais homogêneos e/ou adensamento de remanescentes de ervais nativos estão impulsionando a procura por mudas de erva-mate. No entanto, as mudas utilizadas para o estabelecimento dos ervais são geralmente provenientes de viveiros que não possuem programas efetivos de qualidade, o que tem resultado em plantios com baixa produtividade. Desta forma, LOURENÇO et al. (2000) destacam a importância da qualidade das mudas no estabelecimento de ervais que, dentre vários fatores, é reflexo das propriedades físicas e químicas do substrato.

Dentre vários aspectos que limitam o crescimento das plantas, destaca-se a baixa disponibilidade de fósforo, que ocorre principalmente em solos ácidos (BISSANI et al., 2004). O aproveitamento do $P$ do solo é influenciado pelas características genotípicas das espécies vegetais, as quais se relacionam à capacidade de absorção e à eficiência de utilização deste nutriente (RESENDE et al., 2000). Em condições de deficiência de $\mathrm{P}$ no solo, a baixa absorção deste elemento pode prejudicar o metabolismo de outros nutrientes nos tecidos, principalmente do nitrogênio (MARSCHNER, 1995), uma vez que o P está particularmente envolvido na transferência de energia (SCHUMAN, 1994). O N é um dos nutrientes mais requeridos pelas plantas, participa como constituinte de muitos componentes da célula vegetal, incluindo aminoácidos e ácidos nucléicos. Já o Potássio está envolvido no transporte de carboidratos, síntese de proteínas, expansão celular e movimento estomático, além de ativar enzimas envolvidas na respiração e fotossíntese (TAIZ e ZEIGER, 2004).

De acordo com FLOSS (2006), os conhecimentos relacionados à nutrição das plantas somente promoverão o desenvolvimento quando aplicados adequadamente pelos produtores, para isto, deve-se entender as necessidades nutricionais de cada estádio de crescimento das plantas, a fim de maximizar a produção.

FERNANDES et al. (2000) estudando níveis críticos de fósforo e frações fosfatadas em espécies florestais de aroeirinha (Schinus terenbinthifolius Raddi), paineira (Chorisia speciosa St. Hill.), e jambolão (Sygygium jambolanum Lam.), verificaram que o jambolão é mais exigente que a aroeira. NICOLOSO et al. (2001) verificaram que mudas de grápia (Apuleia leiocarpa Vog. Macbride) responderam à adubação de NPK, porém a planta é muito exigente em $\mathrm{P}$ e medianamente exigente em $\mathrm{K}$ e $\mathrm{N}$ na fase inicial de crescimento. Quanto à ervamate, a resposta à adubação, varia em função do estádio da planta e o tipo de solo e/ou substrato. PANDOLFO et al. (2003), testando doses de NPK em erval jovem, obtiveram resposta significativa da cultura para adubação nitrogenada, porém a aplicação de $\mathrm{K}$ e $\mathrm{P}$ não resultou em resposta significativa para a massa verde das plantas. Já MAZUCHOWSKI (2004), ao testar doses crescentes de $\mathrm{N}$ em mudas de erva-mate constatou que a adubação nitrogenada apresentou ação depressiva nas mesmas.

No caso da erva-mate poucos são os trabalhos que relatam os níveis adequados de nutrientes para a fase de mudas. Portanto, estudos mais aprofundados devem ser desenvolvidos no intuito de determinar a exigência nutricional da espécie nesta fase, importante para o sucesso do futuro plantio e, conseqüentemente do ganho na produtividade.

Diante do exposto, o presente trabalho teve como objetivo avaliar o crescimento inicial de mudas de erva-mate submetidas a doses de nitrogênio, fósforo e potássio.

\section{METODOLOGIA}

Três experimentos foram conduzidos de outubro de 2004 a julho de 2005 em casa de vegetação aberta nas laterais, no Centro Tecnológico de Silvicultura do Departamento de Ciências Florestais pertencente à Universidade Federal de Santa Maria (UFSM), no município de Santa Maria, RS. Os frutos de erva-mate foram coletados no mês de fevereiro de 2004 em erveiras nativas no município de Anta Gorda - RS, e maceradas para extração das sementes. Estas foram lavadas em água corrente, permanecendo à sombra por duas semanas para a secagem. As sementes foram estratificadas utilizando um substrato composto por $50 \%$ de solo (Argissolo Vermelho-Amarelo) coletado da camada de 5 a $15 \mathrm{~cm}$ de profundidade e $50 \%$ de areia de construção com granulometria fina. As sementes foram misturadas ao substrato na proporção 5:1 (v/v), substrato e semente, respectivamente, permanecendo cinco meses em caixa de madeira com umidade adequada. Em agosto de 2004 foram semeadas em sementeira a uma profundidade média de $0,5 \mathrm{~cm}$, utilizando-se como substrato uma mistura de solo $(5$ a $15 \mathrm{~cm}$ de profundidade) peneirado $(5 \mathrm{~mm})$ e areia de 
SANTIN, D. et al. Crescimento de mudas de erva-mate...

construção com granulometria média com proporção 1:1 (v/v), mantendo-as com nível de sombreamento de $50 \%$. Em outubro do mesmo ano, quando as plântulas alcançaram altura média de 5 $\mathrm{cm}$ foram repicadas para vasos (vedados na base) com capacidade volumétrica de $2,2 \mathrm{dm}^{3}$, sendo utilizado $2,0 \mathrm{dm}^{3}$ por vaso de substrato seco ao ar. $\mathrm{O}$ solo utilizado como substrato foi o Argissolo Vermelho-Amarelo (EMBRAPA, 2006), coletado na camada superficial $(0-20 \mathrm{~cm})$, o qual foi passado em peneira de $5 \mathrm{~mm}$ e analisado quimicamente no Laboratório de Solos da UFSM (Tabela 1), conforme metodologia descrita por TEDESCO et al. (1995).

TABELA 1 - Análise química e física do solo utilizado como substrato nos experimentos de produção de mudas de erva-mate (Ilex paraguariensis St. Hil.) com dosagens crescentes de nitrogênio, fósforo e potássio. Santa Maria-RS.

\begin{tabular}{|c|c|c|c|c|c|c|c|c|c|c|c|c|}
\hline \multirow{3}{*}{$\begin{array}{c}\mathrm{pH} \\
\mathrm{H}_{2} \mathrm{O} \\
46\end{array}$} & \multirow{2}{*}{$\begin{array}{l}\text { Índice } \\
\text { SMP } \\
\end{array}$} & $\mathrm{Ca}$ & $\mathrm{Mg}$ & Al & $\mathrm{H}+\mathrm{Al}$ & $\mathrm{CTC}_{\text {efet. }}$ & \multicolumn{2}{|c|}{ Saturação (\%) } & $\mathrm{MO}$ & Argila & $P$ & $\mathrm{~K}$ \\
\hline & & \multicolumn{2}{|c|}{ - - - - - - - - } & $\mathrm{cmol}_{\mathrm{c}} \mathrm{dm}^{-3}$ & $\ldots \ldots$ & $-\cdots--$ & $\mathrm{Al}$ & Base & \multicolumn{2}{|c|}{ - - - (\%) - - - } & \multicolumn{2}{|c|}{$--\mathrm{mg} \mathrm{dm}^{-3}-$} \\
\hline & 4,9 & 2,1 & 0,6 & 2,7 & 15,4 & 5,5 & 49 & 15 & 4,3 & 27,0 & 2,5 & 34,0 \\
\hline
\end{tabular}

Os experimentos testaram as mesmas doses para nitrogênio $(\mathrm{N})$ experimento I, fósforo $(\mathrm{P})$ experimento II, e potássio $(\mathrm{K})$ experimento III. O delineamento experimental utilizado foi de blocos ao acaso, com oito tratamentos, sete blocos e uma planta por vaso para cada elemento testado. Os tratamentos foram: T1-solo sem adição de nutrientes (testemunha), T2-100, T3-200, T4-300, T5-400, T6500 , T7-600 e T8-700 mg kg-1 do elemento testado, correspondendo a $0,200,400,600,800,1.000,1.200$ e $1.400 \mathrm{~kg} \mathrm{ha}^{-1}$, respectivamente, considerando uma profundidade de 0 a $20 \mathrm{~cm}$ de profundidade e densidade igual a $1 \mathrm{~g} \mathrm{~cm}^{-3}$. Utilizando-se como fontes, $\mathrm{N}$ (uréia), $\mathrm{P}$ (superfosfato triplo-SFT) e $\mathrm{K}$ (cloreto de potássio-KCl). Como o solo apresentou nível muito baixo para $\mathrm{P}$ e baixo para $\mathrm{K}$ (SOCIEDADE BRASILEIRA DE CIÊNCIA DO SOLO, 2004), corrigiuse o mesmo com $90 \mathrm{mg} \mathrm{dm}^{-3}$ de $\mathrm{P}$ e $150 \mathrm{mg} \mathrm{dm}^{-3} \mathrm{de}$ $\mathrm{K}$, utilizando-se as mesmas fontes dos tratamentos, somente quando estes elementos não constituíam o tratamento.

As doses de correção de $\mathrm{P}$ e $\mathrm{K}$ e, os tratamentos de $\mathrm{P}$ e $50 \%$ da dose de cada tratamento de $\mathrm{N}$ e $\mathrm{K}$ foram incorporados ao solo antes da repicagem das mudas. Para isto, homogeneizouse o solo com os adubos em sacos plásticos, por repetição. Após 20 dias da repicagem das mudas aplicou-se na superfície o restante das doses de $\mathrm{N}$ e $\mathrm{K}$, dissolvidas em água.

No primeiro mês após a repicagem, as mudas foram mantidas com sombreamento de $70 \%$. Após a fase inicial de pega até o final do experimento, o nível de sombra foi de $30 \%$ e, a umidade do solo foi mantida em torno de $75 \%$ da capacidade de campo, repondo-a conforme necessidade, mediante pesagem dos vasos.

Após 270 dias da repicagem das mudas coletaram-se dados de altura total, medindo-se as mesmas com régua $(\mathrm{cm})$, do nível do solo até o ápice e, o diâmetro do colo mediu-se com paquímetro $(\mathrm{mm})$ a $0,5 \mathrm{~cm}$ do solo. Em seguida determinou-se a matéria fresca da parte aérea com balança de precisão. As raízes foram lavadas utilizando-se peneiras de $2 \mathrm{~mm}$ para evitar possíveis perdas de raízes. As amostras da parte aérea e de raízes foram acondicionadas em sacos de papel devidamente identificados e secas em estufa a 60 ${ }^{\circ} \mathrm{C}$, com ventilação forçada até peso constante.

Foram analisadas as variáveis altura total $(H)$, diâmetro do colo (DC), matéria fresca da parte aérea (MFPA), matéria seca da parte aérea (MSPA), matéria seca da raiz (MSR), matéria seca total (MST) e dose de máxima eficiência técnica (DMET).

Os dados foram submetidos a análise de variância (ANOVA) e analisados por regressão polinomial a $5 \%$ de probabilidade de erro, utilizandose os valores das repetições.

\section{RESULTADOS E DISCUSSÃO}

\section{Experimento I (N)}

A adubação nitrogenada nas doses aplicadas promoveu efeitos negativos para todas as variáveis analisadas, sendo que a testemunha apresentou os melhores resultados, indicando suprimento adequado do solo para este nutriente (Tabela 1). Para a MSR ocorreu efeito quadrático em relação às diferentes doses de $\mathrm{N}$ testadas, com ponto de mínimo em aproximadamente $590,4 \mathrm{mg}$ $\mathrm{kg}^{-1}$ de N (Figura 1A). A MSPA, MST (Figura 1A) e MFPA (Figura 1B) apresentaram decréscimos de aproximadamente 66,70 e $63 \%$ na dose de $700 \mathrm{mg}$ $\mathrm{kg}^{-1}$ de $\mathrm{N}$ em relação à testemunha, respectivamente. Para as variáveis $H$ e DC também ocorreram decréscimos com o aumento das doses de $\mathrm{N}$ (Figura $1 \mathrm{C}$ e $\mathrm{D}$ ). $\mathrm{A} \mathrm{H}$ foi reduzida em aproximadamente $54 \%$ em relação à testemunha para a dose de $700 \mathrm{mg} \mathrm{kg}^{-1}$ de N. O DC teve ponto de mínimo para valores de $324 \mathrm{mg} \mathrm{kg}^{-1}$ de $\mathrm{N}$ e ponto de máximo para $396 \mathrm{mg} \mathrm{kg}^{-1}$ de $\mathrm{N}$, sendo que o ponto de inflexão da curva ocorreu em $360 \mathrm{mg} \mathrm{kg}^{-1}$ de $\mathrm{N}$. 
SANTIN, D. et al. Crescimento de mudas de erva-mate...
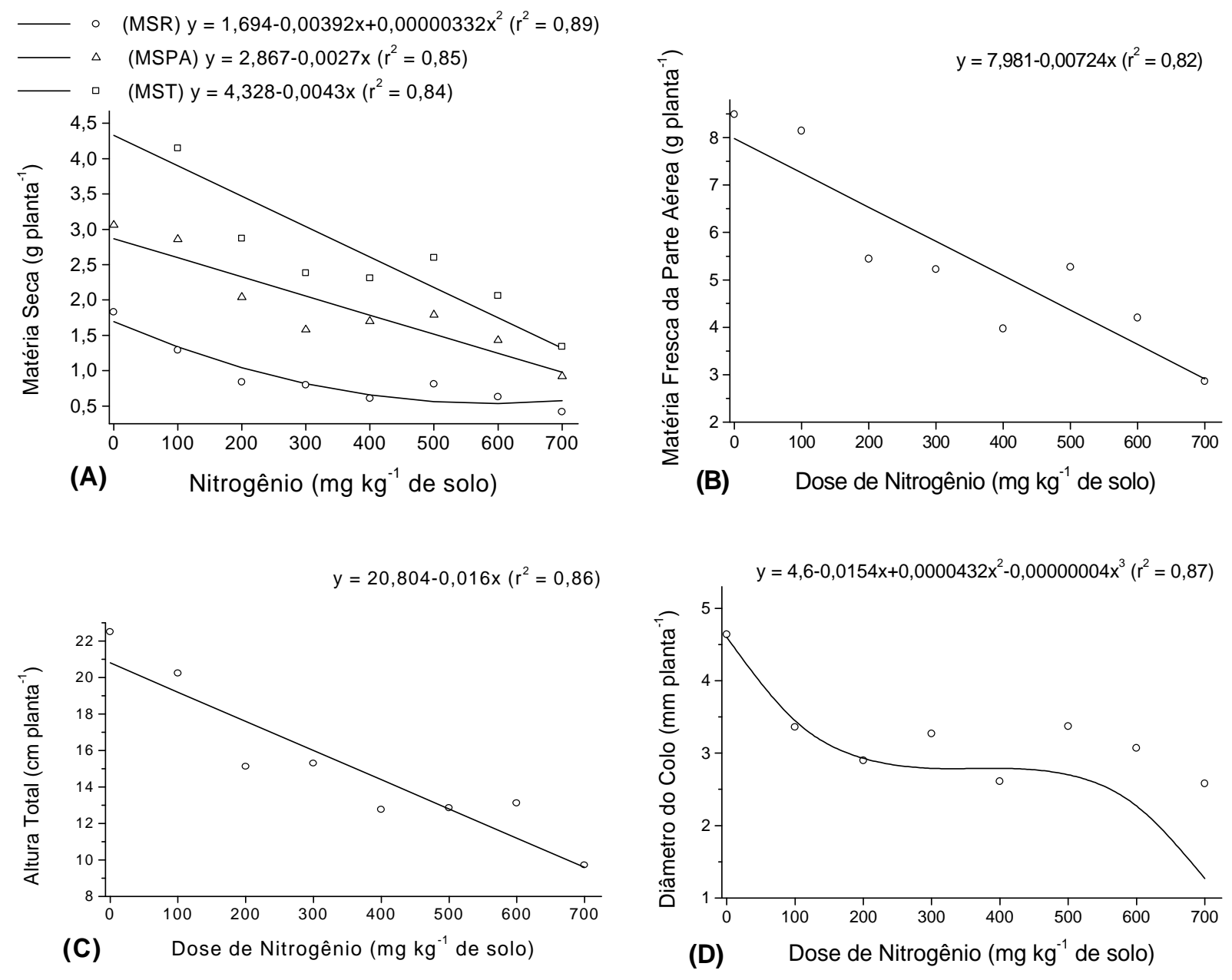

FIGURA 1 - (A) matéria seca da raiz, parte aérea e total; (B) matéria fresca da parte aérea, (C) altura total e (D) diâmetro do colo de mudas de erva-mate (Ilex paraguariensis St. Hil.) cultivadas em diferentes doses de nitrogênio, aos 270 dias.

Resultados semelhantes foram verificados por MAZUCHOWSKI (2004), ao testar doses de 0; $10 ; 20$ e $30 \mathrm{~g} \mathrm{dm}^{-3}$ de $\mathrm{N}$ em mudas de erva-mate em Organossolo Háplico, observou que a adição de nitrogênio demonstrou ser ineficiente e causadora da mortalidade de plantas, concluindo que o excesso de nitrogênio resultou em condições estressantes para o desenvolvimento da planta. Entretanto, em estudos realizados por PINTRO et al. (1998) com adição de $50 \mathrm{mg} \mathrm{dm}^{-3}$ de $\mathrm{N}$ em mudas de erva-mate foi verificado aumento significativo para altura, número de folhas, área foliar e para produção de biomassa, quando comparada à testemunha (Latossolo Roxo Distrófico com $3,0 \mathrm{~g} \mathrm{dm}^{-3} \mathrm{de}$ carbono). Porém, ZAMPIER (2001) observou que o aumento do $\mathrm{N}$ limitou a produção de biomassa foliar para mudas dessa espécie.
Apesar da concentração de N nas folhas de erva-mate ser expressiva, segundo WISNIEWSKI et al. (1996) de $17,4 \mathrm{~g} \mathrm{~kg}^{-1}$ para plantas com dois anos e, para plantas adultas, $21,9 \mathrm{~g} \mathrm{~kg}^{-1}$ (REISSMANN et al., 1999) e 29,6 $\mathrm{g} \mathrm{kg}^{-1}$ (BORILLE et al., 2005) mesmo assim, as plantas não responderam aos tratamentos. Desta forma, uma possível resposta positiva ao $\mathrm{N}$, poderia ser verificada com doses menores, considerando que o substrato (Tabela 1) apresentava apenas nível médio de matéria orgânica (SOCIEDADE BRASILEIRA DE CIÊNCIA DO SOLO, 2004). Por outro lado, segundo CARNEIRO (1995), doses elevadas de $\mathrm{N}$ afetam a qualidade fisiológica das mudas, resultando em efeitos negativos no desenvolvimento. Além disso, BISSANI et al. (2004) comentam que o suprimento de $\mathrm{N}$ em excesso pode 
ocorrer facilmente, o que não é comum com os outros nutrientes.

\section{Experimento II $(\mathrm{P})$}

Com o aumento das doses de $\mathrm{P}$ observouse incremento para todas as variáveis analisadas em relação à testemunha. A MSR, MSPA, MST (Figura 2A) e MFPA (Figura 2B) apresentaram comportamento quadrático, com dose de máxima eficiência técnica (DMET) de 410,7; 438,8; 430,3 e
$436,8 \mathrm{mg} \mathrm{kg}^{-1}$ de $\mathrm{P}$, respectivamente. A H e DC (Figura 2C e D) apresentaram comportamento quadrático com DMET correspondente a 533,0 e 435,2 $\mathrm{mg} \mathrm{kg}^{-1}$ de $\mathrm{P}$, respectivamente. Estes resultados corroboram com CECONI et al. (2007), que obtiveram o melhor crescimento das mudas de erva-mate nas doses de 360 e $450 \mathrm{mg} \mathrm{kg}^{-1}$ de P. No entanto, PANDOLFO et al. (2000) ao trabalharem com diferentes doses de $\mathrm{P}$ em plantio de erval a campo, constataram que as plantas não responderam à adubação fosfatada.
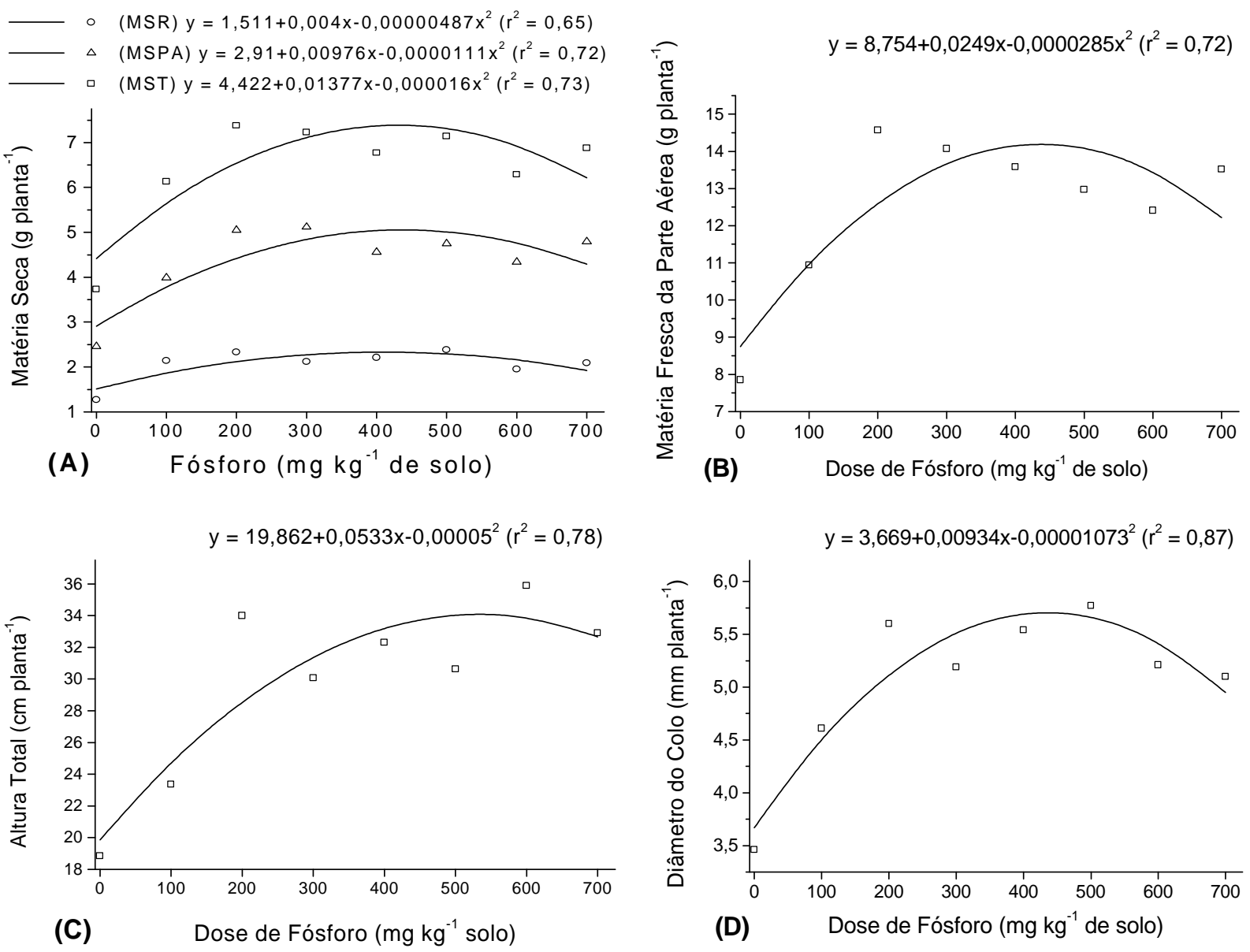

FIGURA 2 - (A) matéria seca da raiz, parte aérea e total; (B) matéria fresca da parte aérea, (C) altura total e (D) diâmetro do colo de mudas de erva-mate (Ilex paraguariensis St. Hil.) cultivadas em diferentes doses de fósforo, aos 270 dias.

A resposta significativa a doses crescentes de $\mathrm{P}$ pode ter ocorrido, devido o substrato de cultivo (Tabela 1) apresentar nível muito baixo deste elemento (SOCIEDADE BRASILEIRA DE CIÊNCIA DO SOLO, 2004), pois em condições de $\mathrm{pH}$ ácido, o $\mathrm{P}$ fica fortemente adsorvido nas partículas do solo (BARROW, 1985), limitando sua disponibilidade às plantas. Este fato também é sustentado por NEVES et al. (1990), que ao trabalhar com eucalipto, concluíram que a disponibilidade natural de $\mathrm{P}$ é muito pequena e, conseqüentemente, as respostas das plantas podem ser de grande magnitude.

Devido aos baixos teores encontrados nas folhas aliado à característica da espécie de ocorrer espontaneamente em solos pobres, a erva-mate sempre foi considerada pouco exigente em $P$ (RADOMSKI et al.,1992; REISSMANN et al., 1983). Porém, a obtenção de resposta a altos níveis de $\mathrm{P}$ 
SANTIN, D. et al. Crescimento de mudas de erva-mate...

neste trabalho e por CECONI et al. (2007) se contrapõe àqueles pontos de vista, defendido até o momento, de baixa exigência da cultura a este nutriente.

No presente estudo, os dados mostram a resposta da erva-mate ao $\mathrm{P}$ aplicado em altas doses, motivado por questões ainda não esclarecidas, como por exemplo, a inibição dos mecanismos vinculados a rizosfera que possibilitam o aproveitamento do $\mathrm{P}$ nativo em condições adversas. Isto porque pouco se conhece sobre o mecanismo que esta espécie possui quanto à eficiência de absorção do P. Este fato poderia ser elucidado em paralelo com a análise foliar, verificando inclusive, o comportamento do $\mathrm{Zn}$, que segundo BROWN et al. (1970) pode ser inibido na presença de altas doses de $\mathrm{P}$ por efeito de diluição ou por antagonismo, ou ainda, pela formação de compostos insolúveis de Zn com P na planta ou no solo.

\section{Experimento III (K)}

Em relação ao $K$, constatou-se que as variáveis analisadas, com exceção da MFPA, apresentaram valores inferiores à testemunha, assim, de maneira geral, quanto maior a dose de $\mathrm{K}$ maior o efeito negativo. A MSR, MSPA e MST demonstraram efeito linear decrescente em relação ao aumento das doses de $\mathrm{K}$ testadas, com reduções de 87,$2 ; 82,6$ e $84,1 \%$ na dose de $700 \mathrm{mg} \mathrm{kg}^{-1}$ de $\mathrm{K}$ em relação à testemunha, respectivamente (Figura 3A). A MFPA apresentou comportamento de efeito cúbico com ponto de mínimo para valores de 673,7 $\mathrm{mg} \mathrm{kg}^{-1}$ de $\mathrm{K}$ e ponto de máximo para $149,7 \mathrm{mg} \mathrm{kg}^{-1}$ de $\mathrm{K}$, sendo que o ponto de inflexão da curva ocorreu em 411,7 $\mathrm{mg} \mathrm{kg}^{-1}$ de K (Figura 3B).
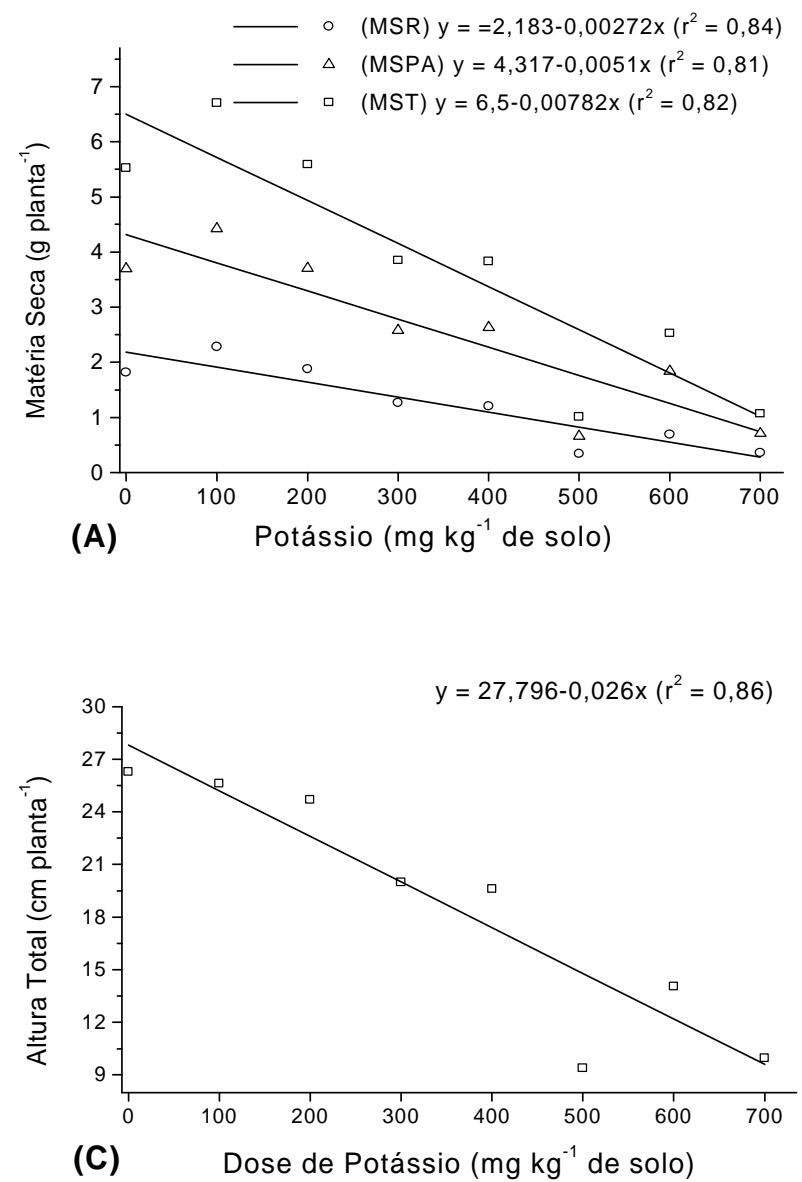

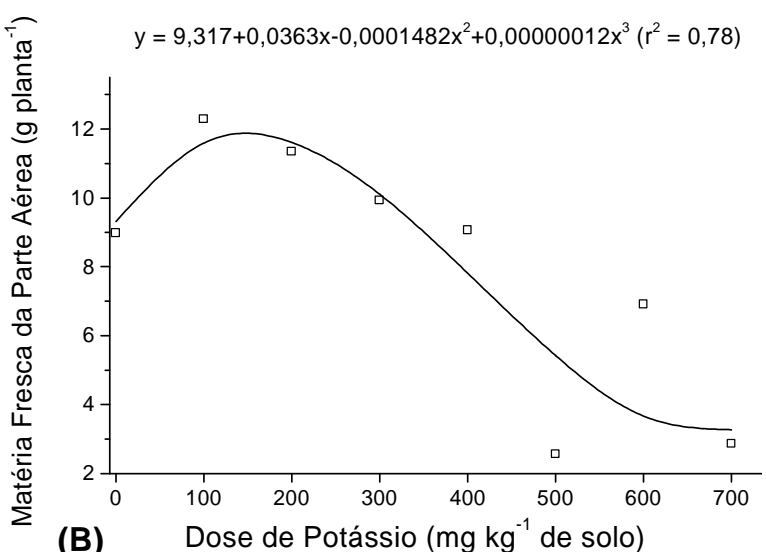

(B) Dose de Potássio ( $\mathrm{mg} \mathrm{kg}^{-1}$ de solo)

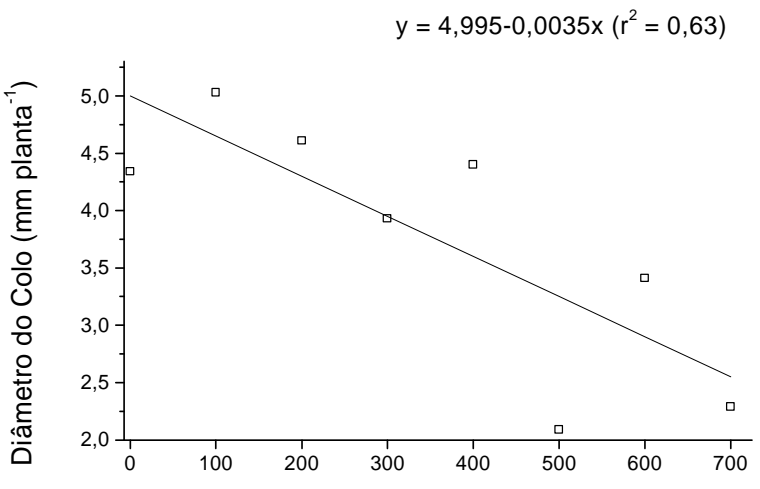

(D) Dose de Potássio ( $\mathrm{mg} \mathrm{kg}^{-1}$ de solo)

FIGURA 3 - (A) matéria seca da raiz, parte aérea e total; (B) matéria fresca da parte aérea, (C) altura total e (D) diâmetro do colo de mudas de erva-mate (Ilex paraguariensis St. Hil.) cultivadas em diferentes doses de potássio, aos 270 dias após a repicagem. 
O efeito superior do ponto de máximo para MFPA em relação à testemunha, porém não verificado na MSPA, pode estar relacionado ao maior conteúdo de água acumulado no interior das células. Segundo MARSCHNER (1995) esse efeito é altamente relacionado com teores de $\mathrm{K}$ existentes na planta. A altura total (Figura 3C) e diâmetro do colo (Figura 3D) das mudas diminuíram linearmente com o aumento das doses de $\mathrm{K}$, com reduções de 65,5 e $49,0 \%$ na dose de $700 \mathrm{mg} \mathrm{kg}^{-1}$ de $\mathrm{K}$ em relação a testemunha, respectivamente.

Ao avaliar o crescimento e desenvolvimento de mudas de erva-mate cultivadas em solo sob diferentes níveis de fertilidade, PINTRO et al. (1998), verificaram que a dose de $150 \mathrm{mg} \mathrm{dm}^{-3}$ de $\mathrm{K}_{2} \mathrm{O}$ não apresentou resposta significativa para as variáveis estudadas. Entretanto, PANDOLFO et al. (2003) ao analisarem o rendimento de biomassa em erval jovem submetido à adubação mineral e orgânica em Latossolo, concluíram que a resposta da ervamate ao $\mathrm{K}$ está relacionada aos teores do nutriente existente no solo. Assim, os teores de $\mathrm{K}$ no solo abaixo de $120 \mathrm{mg} \mathrm{dm}^{-3}$, com aplicação anual de 75 $\mathrm{g}$ de $\mathrm{K}_{2} \mathrm{O}$ por planta, resultaram em uma produção de massa verde em torno da resposta máxima. Quando os teores de K apresentavam-se acima deste nível, a aplicação anual de $25 \mathrm{~g}$ de $\mathrm{K}_{2} \mathrm{O}$ por planta foi suficiente para manter a produção de massa verde.

Devido ao baixo teor de $\mathrm{K}$ no substrato (Tabela 1) (SOCIEDADE BRASILEIRA DE CIÊNCIA DO SOLO, 2004), esperava-se resposta positiva ao aumento das doses do nutriente neste estudo. Além disso, sendo a concentração de $\mathrm{K}$ na matéria seca foliar de mudas de erva-mate relevante, 8,52 a 21,2 $\mathrm{g} \mathrm{kg}^{-1}$ (ZAMPIER, 2001) e 13,6 a 19,6 g kg-1 (REISSMANN et al., 1999), assim como em plantas adultas 16,9 a $14,7 \mathrm{~g} \mathrm{~kg}^{-1}$ (REISSMANN e CARNEIRO, 2004) e $7,7 \mathrm{~g} \mathrm{~kg}^{-1}$ (CARNEIRO et al., 2006) os mesmos sugerem alta exigência da espécie em K. Porém, nesta investigação, constatou-se baixa resposta ao $\mathrm{K}$, sendo que, resposta positiva poderia ser verificada com adição de doses menores às testadas.

Poucos são os casos de toxidez por $\mathrm{K}$ em plantas, no entanto, o excesso deste, pode interferir positiva ou negativamente na absorção de outros cátions pelas plantas. Este fato ocorre desde que haja competição direta com o mesmo sítio de absorção, sendo que teores mais altos de $\mathrm{K}$ na planta aumentam a taxa de absorção de $\mathrm{NO}_{3}^{-}$, e pode inibir as de $\mathrm{Ca}$ e $\mathrm{Mg}$ (MARSCHNER, 1995). No entanto, devido ao substrato de estudo (Tabela 1) apresentar teores de $\mathrm{Ca}$ e $\mathrm{Mg}$ no limite inferior do nível médio (SOCIEDADE BRASILEIRA DE CIÊNCIA DO SOLO, 2004), as respostas negativas do $\mathrm{K}$ para a maioria das variáveis, pode ter resultado da provável redução na absorção de $\mathrm{Ca}$ e $\mathrm{Mg}$ pelas plantas.

Os resultados mostraram que, exceto para a MFPA no tratamento com K, doses de $\mathrm{N}$ e $\mathrm{K}$ acima de $100 \mathrm{mg} \mathrm{kg}^{-1}$ mostraram-se prejudiciais às mudas. No entanto, mesmo na dose mais elevada de N, P e K não se constatou mortalidade das mesmas.

Desta forma, para melhor entender este comportamento é importante novos estudos a fim de estabelecer níveis críticos para N, P e K, além de determinar a exigência nutricional, testando doses menores para $\mathrm{N}$ e $\mathrm{K}$. Pois para DECHEN e NACHTIGALL (2007), cada nutriente possui papel específico no metabolismo das plantas e o desequilíbrio entre as proporções destes, podem causar deficiência ou excesso, limitando o crescimento das plantas ou mesmo levando-as a morte.

\section{CONCLUSÕES}

Nas condições experimentais os resultados obtidos permitem concluir que:

1) As mudas de erva-mate responderam ao $P$ aplicado. $O$ efeito positivo de $P$ nas variáveis massa seca radicular, massa seca da parte aérea, massa seca total, massa fresca da parte aérea, altura total e diâmetro do colo foi observado na dose média de máxima eficiência técnica de $447 \mathrm{mg} \mathrm{kg}^{-1}$.

2) Embora as mudas tenham apresentado resposta de máxima eficiência técnica na dose de $149,7 \mathrm{mg} \mathrm{kg}^{-1}$ de $\mathrm{K}$ para massa fresca da parte aérea, doses de $\mathrm{N}$ e $\mathrm{K}$ superiores a $100 \mathrm{mg} \mathrm{kg}^{-1} \mathrm{de}$ substrato, mostraram-se inviáveis para produção de mudas de erva-mate.

\section{AGRADECIMENTO}

Em especial ao professor Juarez Martins Hoppe (in memorian) pela oportunidade, apoio e dedicação.

\section{REFERÊNCIAS}

1. BARROW, N.J. Reaction of anions and cations with variable-charge soils. Advances in Agronomy, v. 38, p. 183230,1985 .

2. BISSANI, C.A.; GIANELLO, C.; TEDESCO, M.J.; CAMARGO, F.A.O. Fertilidade dos solos e manejo da adubação de culturas. Porto Alegre: Gênesis, 2004. 328 p.

3. BORILLE, A.M.W.; REISSMANN, C.B.; FREITAS, R.J.S.de. Relação entre compostos fitoquímicos e nitrogênio em morfotipos de erva-mate (Ilex paraguariensis St. Hil.). Boletim Centro de Pesquisa de Processamento de Alimentos, v. 23, n. 1, p. 183-198, 2005

4. BROWN, A.L.; KRANTZ, B.A.; EDDINGS, J.L. Zinc-phosphorus interactions as measured by plant response and soil analysis. Soil Science, v. 110 , p. 415-420, 1970.

5. CARNEIRO, J.G. de A. Produção e controle de qualidade de mudas florestais. Curitiba: UFPR/FUPEF; Campos: UENF, 1995. $451 \mathrm{p}$.

6. CARNEIRO, C.; REISSMANN, C.B.; MARQUES, R. Comparação de métodos sw análise química de K, Ca, Mg e Al, em folhas de erva-mate (Ilex paraguariensis St. Hil.). Cerne, v. 12, n. 2, p. 113-122, 2006. 
SANTIN, D. et al. Crescimento de mudas de erva-mate...

7. CARVALHO, P.H.R. Espécies arbóreas brasileiras. Brasília: Embrapa Informação tecnológica; Colombo: Embrapa Florestas, 2003. $1039 \mathrm{p}$.

8. CECONI, D.E.; POLETTO. I.; LOVATO. T.; MUNIZ, M.F.B. Exigência nutricional de mudas de erva-mate (llex paraguariensis a. St.-Hil.) à adubação fosfatada. Ciência Florestal, v. 17, n. 1, p. 25-32, 2007.

9. DA CROCE, D.M.; FLOSS, P.A. Cultura da erva-mate no Estado de Santa Catarina. Chapecó: EPAGRI-CPPP, 1999. 81 p. (Boletim Técnico, 100).

10. DECHEN, A.R.; NACHTIGALL, G.R. Elementos requeridos à nutrição de plantas. In: NOVAIS, R.F.; ALVAREZ VENEGAS, V.H.; BARROS, N.F.; FONTES, R.L.F.; CANTARUTTI, R.B.; NEVES, J.C.L. (Eds.). Fertilidade do Solo. Viçosa: Sociedade Brasileira de Ciência do Solo, 2007. p. 91-132.

11. EMBRAPA. Empresa Brasileira de Pesquisa Agropecuária. Sistema brasileiro de classificação de solos. 2. ed. Rio de Janeiro: Embrapa Solos, 2006. 306 p.

12. FERNANDES, L.A.; FURTINI NETO, A.E.; FONSECA, F.C.; DO VALE, F.R. Crescimento inicial, níveis críticos de fósforo e frações fosfatadas em espécies florestais. Pesquisa Agropecuária Brasileira, v. 35, n. 6, p. 1191-1198, 2000.

13. FLOSS, E.L. Fisiologia das plantas cultivadas: o estudo do que está por trás do que se vê. 3. ed. Passo Fundo: Editora Universidade de Passo Fundo, 2006. 751 p.

14. LOURENÇO, R.S.; MEDRADO, M.J.S.; FOWLER, J.A.P.; MOSELE, S.H. Influência do substrato no desenvolvimento de mudas de erva-mate (llex paraguariensis St. Hill.). Perspectiva, v. 24, n. 88, p. 81-99, 2000.

15. MACCARI JUNIOR, A.; MAZUCHOWSKI, J.Z. Produtos alternativos e desenvolvimento da tecnologia industrial na cadeia produtiva da erva-mate. Curitiba: Câmara Setorial Produtiva da Erva-Mate do Paraná, 2000. 160 p.

16. MARSCHNER, H. Mineral nutrition of higher plants. 2. ed. London: Academic Press, 1995. $889 \mathrm{p}$.

17. MAZUCHOWSKI, J.Z. Influência de níveis de sombreamento e de nitrogênio na produção de massa foliar da erva-mate Ilex paraguariensis St. Hil. Curitiba, 2004. 113 f. Dissertação (Mestrado em Ciência do Solo Fertilidade do Solo e Nutrição de Plantas) - Curso de Pós-Graduação em Ciência do Solo, Setor de Ciências Agrárias, Universidade Federal do Paraná.

18. NEVES, J.C.L.; GOMES, J.M.; NOVAIS, R.F. Fertilização mineral de mudas de eucalipto. In: BARROS, N.F.; NOVAIS, R.F. (Eds.) Relação solo-eucalipto. Viçosa: Editora Folha de Viçosa, 1990. p. 99-126.

19. NICOLOSO, F.T.; FOGAÇA, M.A.de.F.; ZANCHETTI, F.; MISSIO, E. Nutrição mineral de mudas de grápia em Argissolo vermelho Distrófico Arênico: (I) Efeito da adubação NPK no crescimento. Ciência Rural, v. 31, n. 6, p. 991-998, 2001.

20. PANDOLFO, C.M.; FLOSS, P.; DA CROCE, D.M. Resposta da erva-mate a doses de nitrogênio, fósforo, potássio e esterco de aves, em um Latossolo Roxo distrófico. In: CONGRESSO SUL-AMERICANO DA ERVA-MATE, 2.; REUNIÃO TÉCNICA DO CONE SUL SOBRE A CULTURA DA ERVA-MATE, 3., 2000, Porto Alegre. Anais. Porto Alegre: Comissão dos Organizadores, Universidade do Rio Grande do Sul, Fundação Estadual de Pesquisa Agropecuária, 2000. p. 2023.

21. PANDOLFO, M.C.; FLOSS, P.A.; DA CROCE, D.M.; DITTRICH, R.C. Resposta da erva-mate (Ilex paraguariensis St. Hil.) à adubação mineral e orgânica em um Latossolo Vermelho aluminoférrico. Ciência Florestal, v. 13, n. 2, p. 37-45, 2003.

22. PINTRO, J.C.; MATUMOTO-PINTRO, P.T.; SCHWAN-ESTRADA, K.R.F. Crescimento e desenvolvimento de mudas de erva-mate (Ilex paraguariensis St. Hil.) cultivadas em solo sob diferentes níveis de fertilidade. Acta Scientiarum, v. 20, n. 3, p. 285-289, 1998.

23. RADOMSKI, M.I.; SUGAMOSTO, M.L.; GIAROLA, N.F.B.; CAMPIOLO, S. Avaliação dos teores de macro e micronutrientes em folhas jovens e velhas de erva-mate nativa. Revista do Instituto Florestal, v. 4, (Edição Especial), p. 453-456, 1992.

24. REISSMANN, C.B.; CARNEIRO, C. Crescimento e composição química de erva-mate (Ilex paraguariensis St. Hil.), transcorrido oito anos de calagem. Revista Floresta, v. 34, n. 3, p. 381-386, 2004.

25. REISSMANN, C.B.; ROCHA, H.O. da; KOEHLER, W.C.; CALDAS, R.L.S.; HILDEBRAND, E.E. Bio-elementos em folhas e hastes de erva-mate (Ilex paraguariensis St. Hill.) sobre cambisolos na região de Mandirituba - PR. Revista Floresta, v. 14. n. 2, p. 49-54, 1983

26. REISSMANN, C.B.; RADOMSKI, M.I.; QUADROS, R.M.B. de. Chemical composition of Ilex paraguariensis St. Hil. Under different management conditions in seven localities of Paraná State. Brazilian Archives of Biology and Technology, v. 42, n. 2, p. 187-194, 1999

27. RESENDE, A.V. FURTINI NETO, A.E.; CURI, N.; MUNIZ, J.A.; FARIA, M.R.de. Acúmulo e eficiência nutricional de macronutrientes por espécies florestais de diferentes grupos sucessionais em resposta à fertilização fosfatada. Ciência Agrotécnica, v. 24, n. 1, p. 160-173, 2000.

28. SCHUMAN, L.M. Mineral nutrition. In: WILKINSON, R.E. (Ed.). Plant-environment interactions. New York: Marcel Dekker, 1994. p. 149-182.

29. SOCIEDADE BRASILEIRA DE CIENCIA DO SOLO. COMISSÃO DE QUÍMICA E FERTILIDADE DO SOLO. Manual de adubação e calagem para os Estados do Rio Grande do Sul e Santa Catarina. 10 ed. Porto Alegre, 2004. 400 p.

30. TAIZ, L.; ZEIGER, E. Fisiologia vegetal. 3. ed. Tradução de: Eliane Romanato Santarém [et al.]. Porto Alegre: Artmed, 2004. 719 p.

31. TEDESCO, M.J.; GIANELLO, C.; BISSANI, C.A.; BOHNEN, H.; VOLKWEISS, S.J. Análises de solo, plantas e outros materiais. Porto Alegre: UFRGS-Departamento de Solos, 1995. p. 21 e 89-95. (Boletim técnico, 5).

32. WISNIEWSKI, C.; JINZENJI, F.; CLARO, A.M.; SOUZA, R.M. de. Exportação de biomassa e macronutrientes com a primeira poda de formação da erva-mate na região de Pinhais - PR. Revista do Setor de Ciências Agrárias, v. 15, n. 2, p. 179-186, 1996

33. ZAMPIER, A.C. Avaliação dos níveis de nutrientes, cafeína e taninos em erva-mate (Ilex paraguariensis St. Hil) após adubação, e sua relação com a produtividade. Curitiba, 2001. 94 f. Dissertação (Mestrado em Engenharia Florestal) - Setor de Ciências Agrárias, Universidade Federal do Paraná. 
